\title{
Howard Goldblatt's Translation Practice and Translation Thoughts
}

Yunchao Zuo, Chwee Fang Ng, Sabariah Md Rashid, Florence H. C. Toh.

To Link this Article: http://dx.doi.org/10.6007/IJARBSS/v11-i5/9829

DOI:10.6007/IJARBSS/v11-i5/9829

Received: 16 March 2021, Revised: 20 April 2021, Accepted: 02 May 2021

Published Online: 27 May 2021

In-Text Citation: (Zuo et al., 2021)

To Cite this Article: Zuo, Y., Ng, C. F., Rashid, S. M., \& Toh., F. H. C. (2021). Howard Goldblatt's Translation Practice and Translation Thoughts. International Journal of Academic Research in Business and Social Sciences, 11(5), 569-578.

\section{Copyright: (c) 2021 The Author(s)}

Published by Human Resource Management Academic Research Society (www.hrmars.com)

This article is published under the Creative Commons Attribution (CC BY 4.0) license. Anyone may reproduce, distribute, translate and create derivative works of this article (for both commercial and non-commercial purposes), subject to full attribution to the original publication and authors. The full terms of this license may be seen at: http://creativecommons.org/licences/by/4.0/legalcode

\section{Vol. 11, No. 5, 2021, Pg. 569 - 578}

Full Terms \& Conditions of access and use can be found at http://hrmars.com/index.php/pages/detail/publication-ethics 


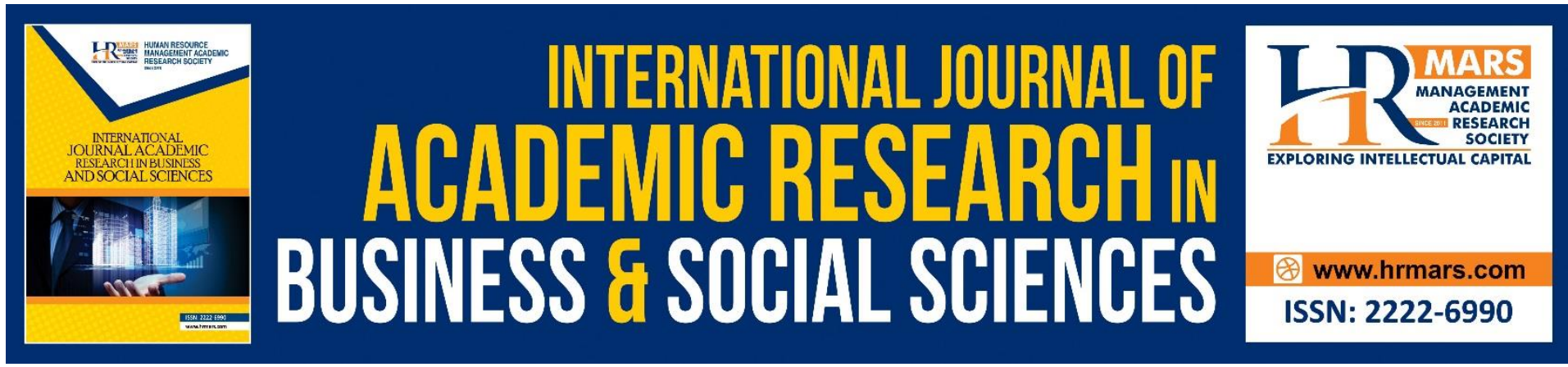

\title{
Howard Goldblatt's Translation Practice and Translation Thoughts
}

\author{
Yunchao Zuo, Chwee Fang Ng, Sabariah Md Rashid, Florence \\ H. C. Toh.
}

Faculty of Modern Language and Communication, Universiti Putra Malaysia, 43400 Serdang, Selangor, Malaysia

Email: chweefang@upm.edu.my

\begin{abstract}
With the cultural turn of translation studies, the subject status of translators has gradually been highlighted, and translator studies have become increasingly important. However, the current research on translators is mostly confined to certain aspects such as the translator's translation thoughts, translation strategies or translation styles, which lacks comprehensive and detailed research. This article aims to study the translator Howard Goldblatt from the four aspects of his life experience, namely translation practice, translation motivation, translation thoughts and translation strategies, in an attempt to present a detailed and comprehensive translator. The results demonstrate that Howard Goldblatt's translation is based on cross-cultural communication as the ultimate goal, comprehensively using translation strategies that combine domestication and foreignization to spread the Chinese culture. This study contributes to the diversification of research methods and the dissemination of Chinese culture.
\end{abstract}

Keywords: Translator Research, Translation Thought, Translation Strategies, Howard Goldblatt

\section{Introduction}

As the subject of translation activities, translators are indispensable for translation activities, so translator research is an important content of translation studies. Translation research involves several aspects. Professor Lu Jun made such classifications in his "EnglishChinese Translation Tutorial": "the study of the ontology of translation, the study of the carrier of translation, the study of the object of translation, the study of the environment of translation, the study of the subject of translation, the study of translation control, and the effect of translation the study." According to Professor Lu Jun's classification, translator research is subordinate to he study of the subject of translation. Therefore, translator research should be an important part of translation research.

Howard Goldblatt, a well-known sinologist, was born in California in 1939. He studied Chinese while serving in the military in Taiwan in the 1960s. He received a master of arts from San Francisco State University and a doctorate in Chinese literature from Indiana University. He has successfully translated more than 60 works by more than 30 Chinese writers into 
English, and is the translator who has translated the most Chinese novels in history. Howard Goldblatts' contribution and influence in literary translation and the overseas dissemination of Chinese literature have also made him the focus of attention by scholars, critics, researchers, and media at home and abroad. Especially in recent years, with the continuous improvement of comprehensive national strength, the increase of international influence of China, the continuous progress of media technology and the active interaction between Howard Goldblatt and readers, there have been more and more researches on Howard Goldblatt and his translations at home and abroad. In view of the above facts, it is very necessary to study the translator Howard Goldblatt, which will help recommend the academic community to attach importance to translators' research and overseas Sinology research.

\section{Methods}

This research uses descriptive methods to present Howard Goldblatt's life experience and translation practice, and uses qualitative research methods to analyze his translation motivation, translation thoughts and translation strategies.

By presenting his life and translation practice, this research explores Howard Goldblatt's translation purpose and motivation. Because the translator's life, translation achievements, literary characteristics, translation characteristics, and translation purpose will affect the translator's translation practice and translation motivation; translation motivation affects translation practice, and translation practice in turn reflects translation motivation. These three factors complement each other and influence each other.

By analyzing and studying the translator's selection of words, sentence structure and adjustment of word order, as well as factors such as the translator's translation thoughts, translation principles, and aesthetic appreciation, translator's translation strategies can be analyzed in-depth. The translator's choice of words will of course leave his personal inclinations, so his translation style can be further studied through the analysis of translation strategies.

Using examples and analytical methods, this research analyzes the translator's translation thoughts in detail from the three factors of language, style and culture. Studies have shown that, in order to achieve better translation results, translators should be fully equipped with various background knowledge, learn to use modern media resources, enhance their sense of responsibility, and understand the differences in identities as authors, translators, and readers.

\section{Results and Discussions}

\section{Howard Goldblatt's Translation Experience}

Howard Goldblatt's connection with translation originated from his love for Chinese literature. During his advanced studies at National Taiwan Normal University, he improved his Mandarin level and tried to translate works by Huang Chunming and Wang Zhen. When he was in college, he read the first Chinese novel "The Village in August", and when he went to the library to borrow other works by Xiao Jun, he accidentally saw Xiao Hong's "Hulan River Biography". Since then, he has been studing Xiao Hong and Chinese literature and fall in love with Chinese literature.

The first relatively influential work he translated was the co-translation of Chen Ruoxi's collection of novels "The Chief of Yin County" with Nancy Ing. The English translation was published in 1978 ( Indiana University Press, the English translation is The Execution of Mayor Yin and Other Stories from the Great Proletarian Cultural Revolution). This collection of novels 
is an earlier work describing China's "Cultural Revolution". After its publication, the reaction was strong. The curiosity of foreign readers about the Cultural Revolution also enabled the English translation of this work to be circulated more widely abroad. The most influential publications such as "The New York Times" and "Time Magazine" have published book reviews on this English translation. Whether the evaluation is good or bad, there are always a wave of book reviews. The English version of "Hulan River Biography" published in 1979 is a work worth mentioning in Howard Goldblatt's translation experience. Howard Goldblatt's translation greatly improved Xiao Hong's status, and in turn, Xiao Hong's works also made Howard Goldblatt famous. When Howard Goldblatt visited Yang Xianyi and his wife, he showed them his translation of "Hulan River Biography" and got their approval. At the same time, he also discussed the translation of "Heavy Wings". This novel has been translated by Gladys Yang. Other publishers wanted to ask Howard Goldblatt to translate another version, so Howard Goldblatt went to Beijing to explain it and obtained Gladys's understanding and consent. The English translation of "Heavy Wings" was published in 1900, and it was the first Chinese mainland novel published by Howard Goldblatt with commercial funding. The English translation of "Red Sorghum" published in 1993 brought Howard Goldblatt's translation career to a peak, occupying the most important position in Howard Goldblatt's English translation of Mo Yan. The back cover of this edition quotes Amy Tan's words: "Mo Yan's voice will be introduced into the hearts of American readers, just like Kundera and Garcia Márquez." As Mo Yan's first work to enter American commercial marketing channels, the English translation of The Red Sorghum Family has achieved great success in the United States. It has received a lot of praise in the United States. It has not been out of print for more than 15 years. It has sold more than 15,000 copies. It is not bad to have this number in the United States. Howard Goldblatt's second most influential translation work is Jiang Rong's "Wolf Totem". Since its publication, this work has set off a domestic reading boom. It mainly tells the story of an educated youth who jumped in the Inner Mongolia grassland in the 1960s and 1970s. A story about the interdependence of time with the prairie wolf and nomads. The English translation of "Wolf Totem" has also achieved great success abroad since its publication. Its circulation has set a new record for the sales of foreign translations of Chinese works overseas, and it has also set the record for the highest copyright trade tax on Chinese books. The English translation of "Wolf Totem" has great success and influence abroad.

\section{Howard Goldblatt's Motivation for Translation}

As Ryan \&Deci (2008) described, two types of motivations that drive human activities could be identified, one of which is caused by internal, psychological factors which could be named 'intrinsic motivation', while the other caused by external factors could be called 'eternal rewards'. Translation motivation mainly refers to the psychological process of motivating the translator to perform translation. It is a process that stimulates and encourages the translator to generate an internal driving force and make it move toward the ideal translation goal. Translation motivation, as an important part of the subject of translation, has a significant impact on the choice of translated text and the use of translation strategies. Unlike some translators who translate to support their families, the biggest motivation of Howard Goldblatt's translation is his love for the work and translation. Howard Goldblatt once said: "I am translating, therefore I am here (Goldblatt, 2014a, 221). The most important task of translation is to select, not to translate." Howard Goldblatt selects translation works, usually based on two conditions: "one I like it and the other is that it is suitable for my translation (Goldblatt, 2014a, 221)." As a translator who enjoys translation, 
Howard Goldblatt has full freedom to choose the author and works of his own. Throughout Howard Goldblatt's translation works, although there are some works are translated for other reasons than passion and love for the works, most of his works are what he likes. For example, his translation of "Hulan River Biography" is his favorite work. In order to study Xiao Hong, he even went to Xiao Hong's former residence to inspect it for a long time. Howard Goldblatt's attention to Chinese literature is inseparable from the attraction of Xiao Hong's "Hulan River bibliography" to him. It can be said that Xiao Hong led him into the door of translating Chinese works. Howard Goldblatt wrote in the preface to the translation of "The Commentary on Xiao Hong": "I can't say that I discovered "Xiao Hong's talent and significance-that is the credit of Lu Xun and others, but if this book can further arise everyone's interest in her life, literary creation, and her role in the history of modern Chinese literature, and all my effort's have value." Apart from Xiao Hong, the Chinese writer Howard Goldblatt translated the most works is Mo Yan. He has introduced more than 10 of his works to Western readers. Many critics believe that Howard Goldblatt contributed to Mo Yan's Nobel Prize in Literature. Before that, he had put several Chinese writers on the international literary podium, such as Jiang Rong, Su Tong, and Bi Feiyu. Howard Goldblatt spared no effort to recommend Chinese contemporary novels to the world. Speaking of this, Howard Goldblatt humbly stated that, in fact, he can't claim any credit, but the charm of Chinese writers' works has conquered foreign readers. In 1988, Howard Goldblatt saw Mo Yan's "The Garlic Ballads" and felt very shocked, so he wrote to Mo Yan, hoping to obtain the translation copyright. Mo Yan fully believed in Howard Goldblatt's translation level and said to Howard Goldblatt: "I don't understand English. If you translate it, that's not my novel anymore; it's yours." When the reporter asked which work of Mo Yan he admired the most. At that time, Howard Goldblatt thought for a while to answer: "This is hard to say. I think Mo Yan's most influential novel is "Red Sorghum", and the most representative novel is "Life And Death Are Wearing Me Out". However, I think "The Republic of Wine" is also very good (Zhenqing, 2013)." Howard Goldblatt believes that Mo Yan is a realist writer in his creative style, and he is good at historical novels. No matter which period Mo Yan wrote about the subject matter, he was able to grasp the historical perspective and was able to do his best. He always tried his best to explore the ultimate in Chinese expression and was good at mobilizing various senses. Howard Goldblatt said: "Mo Yan can always combine folk legends, bizarre animal images and various imaginative narrative techniques with history to create unique literary works with attractive themes and lifelike characters. When I first translated Mo Yan's works, Mo Yan was not as famous as it is now, and I am just an American scholar with a Chinese name, but Mo Yan and I appreciate each other. Looking back now, I feel a little proud of, not being able to translate so well, but proud that I discovered such a good writer more than 20 years ago (Wang Zhenqing, 2013)."

\section{Howard Goldblatt's Translation Strategy}

According to the different inclination of the translator towards the original text and the target text, Venuti divided translation strategies into two large categories-domestication and foreignization (Venuti, 2009, p. 240). Xiong Bing defines translation strategy as "a collection of principles and plans adopted to achieve a specific translation purpose in translation activities" (Xiong Bing, 2014). Domestication translation and foreignization translation are two interrelated and complementary strategies. It is impossible for any translation to adopt a single domestication translation or foreignization translation. Foreignization translation is oriented to the original text and adopts the same or similar expression in the source language to convey the original culture of the original text. The use 
of foreignized translation aims to preserve and reflect the characteristics and language styles of foreign nationalities, provide readers with an exotic flavor, attract readers' reading interest, and enrich the expression of the target language. Domestication translation is oriented to target readers and adopts the language norms, reading habits and aesthetic appeal of the target language readers, which helps readers understand the translation more smoothly and increase readability. The choice of translation strategy is affected by factors such as translation motivation, translation purpose, ideology, poetics, patrons, and historical development stages. A translator's translation strategy is not static, and will constantly change in order to adapt to the development of the times. Many researchers believe that Howard Goldblatt's translation is based on domestication, and Howard Goldblatt's translation has been labeled as rewriting, rebellion, and rewriting. However, looking at Howard Goldblatt's translation practice, it can be seen that Howard Goldblatt tried his best to express the characteristics of the original text. If his translated sentences seriously affected the target readers, he would adopt the method of domestication. It can be said that Howard Goldblatt's translation has neither intentional domestication nor intentional foreignization, but flexible use of domestication and foreignization. The domestication and foreignization that he constantly changes and adopts are aimed at the ultimate goal of cross-cultural communication. Examples are as follows:

[1] 看门人爬起来，双手依然捂着头，脸色焦黄，像优质的年糕一样。

The gatekeeper climbed to his feet, still holding his head in his hands. His complexion was sallow, the color of a fine year-end cake.

"Nián gāo" (a fine year-end cake) is a traditional Chinese New Year food with unique Chinese characteristics. The gatekeeper's face was scorched yellow from the gunshot, just like the color of high-quality cakes. Howard Goldblatt has used the word "sallow" to describe the sallow complexion of the gatekeeper, even if the second half of the sentence is not translated, it will not affect the reader's understanding of the story in the target language. However, Howard Goldblatt has adopted an alienation strategy that is very faithful to the original text in order to introduce Chinese cuisine to foreign countries. Although it increases the reading burden of readers, it also stimulates the interest of readers who love Chinese cuisine.

[2] 一个举着寿桃的粉红色裸体男娃咧着小嘴巴哈哈笑，在墙上，在年画上，他的

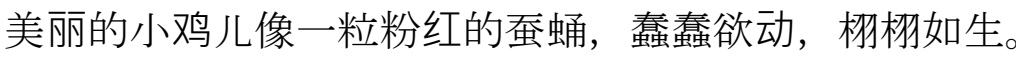

On the wall hung a laughing, pink-skinned, naked toddler with a longevity peach in his hands-a new year's scroll-his darling little pecker poking up like a pink, wriggly silkworm chrysalis. The whole thing was incredibly lifelike.

The description of this sentence plays an important role in the theme of the novel. In order not to affect the artistic characteristics of the original text, Howard Goldblatt adopted a strategy of combining domestication and foreignization to completely translate the original text one by one, and the target language "pecker", which is familiar to readers and spoken words, is used to translate the original "little chicken", which not only reduces the difficulty of reading, but also expresses the original text more faithfully and deepens the theme of the novel.

[3] 汽车的烟雾喷到他们身上。光焰白亮如炭, 孩子们宛若一大串烤熟的小鸟, 撒 了一层红红绿绿的调料, 香气扑鼻。 
Puffy clouds of automobile exhaust settling around them glinted like charcoal in the sunlight and filled the air with their aroma; the children were just like a skewer of roast lamb, basted and seasoned.

The description of this passage reflects the novel "Plot of Braised Baby", which occupies an important position in the description of the full text. While being faithful to the original content, the translator also used the strategy of domestication, translating "children like a bunch of roasted birds" into "children like a bunch of roasted lambs". The combined strategy of domestication and foreignization not only did not reduce the content of the original text, but make the original content more expressive, because the lamb in the Western world symbolizes the inability to protect themselves waiting for slaughter.

[4] 我们这里醉酒的都是些没有知识、没有教养的下里巴人，阳春白雪从来不醉, 您是阳春白雪, 所以您没有醉。”

People around here who get drunk are the dregs of society, illiterates, uncouth people. Highbrow folks, those of the "spring snow," cannot get drunk. You're a highbrow, therefore, you cannot be drunk.

"Yáng chūn bái xuě" (highbrow) is a unique usage of Chinese culture and refers to people with culture and knowledge. It is difficult for the translator to choose between being faithful to the original text and catering for the reader, so he adopts a compromise method, which not only retains the foreign characteristics of the original text, but also translates the substantive connotation of "Yangchun Baixue" through domestication. It not only introduces foreign cultures to readers, but also reduces readers' reading barriers. It can be described as an well polished translation.

[5] 想当年吃花和尚拳打遭青面兽刀杀的青草蛇张三泼皮牛二都在咱酒国留下了后 代，恶种连绵，再有两千年也不会断绝。

I am reminded of the legendary Green Grass Snake Li Four, who was beaten to a pulp by the licentious monk, and Freaky Villain Niu Two, who was stabbed by the Black-Faced Monster. People like that are always hanging around Donkey Avenue - you can't miss them.

"È zhǒng liánmián" (Evil species will never disappear) is an exaggerated artistic technique, highlighting the number of splashes like Niu Two in the republic of wine. "Two thousand years" is not accurate time but refers to very long time. This kind of exaggerated sentence expression is only needed for the plot of the story, so Howard Goldblatt fully considered this situation when translating. For the first half of the sentence he adopts the strategy of foreignization and adopts the strategy of domestication for the second half of the sentence to perfectly describe what the author wants to express more clearly.

\section{Howard Goldblatt's Translation Thoughts}

The first principle is "loyalty"

Faithfulness is the first principle Howard Goldblatt follows when translating. He once mentioned that the translator "must respect the original work" and that the translator "the greatest tutor is the text" (Lu Yanxia, 2008). Through translation examples, it can also be seen that Howard Goldblatt is trying his best to convey the form and content of the original text in order to better spread Chinese culture. For example: Original text: The children looked at him and said in unison "Shen-Jing-Bing-! Translated text: The children looked over at him. Lu-natic-!' they echoed in unison. When Howard Goldblatt translated this sentence, he not only translated the content of the original text completely, but also expressed the form in the text perfectly using amplification translation method. The characters divide the English word 
Lunatic into several parts, and express the unison and elongated voice of the child in the original text just right.

\begin{abstract}
"Betrayal" on the basis of loyalty
Translation is a rewriting of an original text (Lefevere, 1992, p. 1). Howard Goldblatt's "Betrayal" of the original text is a flexible translation principle based on the principle of loyalty, and is a last resort under the current circumstances. At this stage, although the strategy of "Overseas Promotion of Chinese Literature" has been implemented for a long time and some achievements have been made, Chinese literature is still on the margins of world literature, and foreign acceptance level of China is not very high. In the early stage, in order to spread Chinese culture, Howard Goldblatt could only rewrite some content that did not conform to the habits of target language readers. Only when foreign countries have a deeper understanding of Chinese culture can Chinese culture be promoted better. Without an early understanding of Chinese culture, how can Chinese culture go out? Howard Goldblatt's "betrayal" was also an extraordinary act in extraordinary times. In addition, the aesthetics and artistry of literature also require the translator to make appropriate adaptations to the original text. As scholars Xu Jun and Murray emphasized, "literary translation is a more complex process of artistic re-creation that incorporates the translator's thought, emotion, understanding, imagination and aesthetic experience" (Xu Jun and Mu Lei, 2009).
\end{abstract}

Thoughts of translating for readers

From the selection of the translated text to the use of translation strategies, readers have always been Howard Goldblatt's key considerations. His philosophy is: " briefly stated, that the author wrote for his readers, and I translate for mine (Jonathan Stalling, 2014)." A translation without readers and markets becomes useless and therefore loses the meaning of translation. While being faithful to the characteristics of the original text, Howard Goldblatt also paid great attention to the readability and acceptability of the translation. This approach also satisfies the mainstream expectations of western readers and enables his translation to successfully enter the mainstream western market. Between the original author, original text and readers, Howard Goldblatt believes that "the most important thing is to satisfy the needs of the reader, not the author" (Ji Jin, 2009). Therefore, Howard Goldblatt's preface is included in his many English translations. In the preface, he will clearly explain the content that facilitates readers' understanding, such as the original author's introduction, his changes to some of the original text, and so on.

The purpose of translation is cross-cultural communication

Translation is not the forcible inculcation of one country's culture on another, but a twoway interactive process involving the output of the translation and the reader's acceptance. As a bridge between the original author and the target language reader, the translator bears important responsibilities. Howard Goldblatt once mentioned his views on his role, "Whether others think his work is a skill or an art-or both; he is a communicator, an interpreter; he is the main link in the chain of international understanding" (Howard Goldblatt, 2014). Howard Goldblatt loves Chinese literature and is more keen to introduce Chinese literature to Western readers. His rewriting and adaptation of the original text is ultimately for one purpose: to achieve cross-cultural communication. 
The translator should have a sense of responsibility

As an indispensable part of translation thinking, the sense of responsibility of the translator plays a pivotal role in translation practice. A translator who lacks a sense of responsibility can hardly translate a work well. Before translating works, Howard Goldblatt will carefully select the works that suit and attract him. During the translation process, he will humbly discuss with the original author what he does not understand. After the translation is completed, he will revise repeatedly. After his translation is completed, he generally needs five or six revisions; these all show Howard Goldblatt's rigorous translation attitude and strong sense of responsibility.

\section{Conclusion}

Through an in-depth study of Howard Goldblatt's translation practice and thoughts, it is not difficult to find that Howard Goldblatt's translation is based on cross-cultural communication as the ultimate goal, comprehensively using translation strategies that combine domestication and foreignization to spread the Chinese culture as much as possible and meet the psychological expectations of Western readers. Howard Goldblatt's translation practice has great reference and research value for Chinese culture going global. It would be unfair to unilaterally label his translations of betrayal and unfaithfulness. His translation should be viewed objectively, impartially, and dialectically. For works and translation ideas, we must see the problems in his translation without denying his efforts and contributions. No matter which translator's translation strategy or translation thought is, it is the product of a specific history, and it is inevitable that it will bear the marks of a specific period. In the early stage of Chinese culture going global, foreign readers did not know much about Chinese culture; let alone identify with it. Howard Goldblatt's appropriate rewriting and adaptation of the original text on the basis of faithfulness catered to the language habits and aesthetic tastes of Western readers. To meet the needs of the development of the times, it has made a huge contribution to the spread of Chinese culture. However, as China's influence in the world becomes greater and the status of Chinese culture in the world culture is getting higher and higher, foreign readers' interest and needs in Chinese culture are becoming stronger and stronger, and the original text will be rewritten less and less. The more faithful foreignization translation strategy conveying the current culture with Chinese characteristics should become main translation strategy supplemented with domestication translation strategy.

This study contributes to the diversification of research methods, which not only enriches the research on pure language and translation skills, but also enriches the research on cross-cultural communication, and provides important inspiration for the follow-up study of Howard Goldblatt's translator thought. Secondly, this research contributes to the dissemination of Chinese culture and the study of Goldblatt in Sinology, helping to reform the translator's translation thought and way of thinking, and promoting a further study of Goldblatt' translation practice and translation thought.

\section{References}

Goldblatt, H. (1993). Red Sorghum. New York: Viking Penguin.

Goldblatt, H. (1995). The Garlic Ballads. New York: Arcade Publishing.

Goldblatt, H. (2000). The Republic of Wine. New York: Arcade Publishing.

Goldblatt, H. (2001). Shifu, You'll Do Anything for a Laugh. New York: Arcade Publishing.

Goldblatt, H. (2004). Big Breasts and Wide Hips. New York: Arcade Publishing.

Goldblatt, H. (2008). Life and Death are Wearing Me Out. New York: Arcade Publishing. 
Goldblatt, H. (2014a). Sketches by H. Goldblatt. Beijing: Modern Publishing House.

Goldblatt, H. (2014b). How Can Chinese Literature Walk Out (Translated by Lin, Li Jun). Literature Weekly, July, 3.

Ji, J. (2009). Interview with Howard Goldblatt. Contemporary Writer Review, (6): 45-56.

Jonathan, S. (2014). The Voice of the Translator: An Interview with Howard Goldblatt. Translation Review, 88(1): 1-12.

Lefevere, A. (1992). Translation, Rewriting and the Manipulation of Literary Fame. London and New York: Routledge.

Lu, J. \& Hou, X. Q. (2002). English-Chinese Translation Course. Shanghai: Shanghai Foreign Language Education Press, 91.

Lu, Y. X. (2008 March 14). The English Version of "Wolf Totem" was Released Simultaneously Worldwide Yesterday. Beijing Daily.

Ryan, R. M. \& Deci, E. L. (2000). Intrinsic and Extrinsic Motivations: Classic Definitions and New Directions. Contemporary Education Psychology, 54-67.

Venuti, L. (2009). Strategies of Translation. In Mona Baker (Ed.), Routledge Encyclopedia of Translation Studies (pg240). Shanghai: Shanghai Foreign Language Education Press.

Wang, Z. Q. (2013 October 29). Many Outstanding Chinese Works Unknown for Global Readers. Liaoning Daily.

Xiong, B. (2014). Concept Confusion in Translation Studies: Taking "Translation Strategies", "Translation Methods" and "Translation Skills" as Examples. Chinese Translators Journal, 82-88.

Xu, J., \& Mu, L. (2009). Introduction to Translation Studies. Nanjing: Yilin Press. 